

\title{
Highly Self-Organized Materials: Formation Mechanism and Electrochemical Synthesis
}

\author{
DIANA PORTAN ${ }^{1}$, GABRIELA STRNAD², ANDREI MARIAN FEIER ${ }^{3 *}$, OCTAV MARIUS RUSSU $^{3}$ \\ ${ }^{1}$ Composite Materials Group (CMG) Department of Mechanical and Aeronautics Engineering, University of Patras, 26500 Patras, \\ Greece \\ ${ }^{2}$ 'Petru Maior University, Faculty of Engineering, 1 Nicolae lorga Str., 540088, Tirgu Mures, Romania \\ ${ }^{3}$ University of Medicine and Pharmacy, 38 Gheorghe Marinescu Str., 540000, Tirgu Mures, Romania
}

\begin{abstract}
A class of intensively studied materials with application in areas where complex structures with precise geometry are needed (i.e. electronics), are the self-organized nanomaterials. Polymer, metallic and composite self-organized nanomaterials have been in researchers' attention the last decades. They are notonly appealing scientifically, by revealing the intrinsic atomic and molecular interactions that might be difficult to detect otherwise but may also hold the key for the development of novel functional structures and devices. The different mechanisms and forces involved in the self-formation of organized nanostructures are discussed in the presentmanuscript. Further on, key formation fundamentals involved in the fabrication of self-organized nanostructures are described. Between the known manufacturing methods, the electrochemical synthesis is considered extremely simple and cost effective. On the other hand, it involves a wide range of synthesis parameters (e.g. voltage, electrolyte type, temperature, experiment duration, $\mathrm{pH}$ etc.) that may lead to the formation of ingenious structures with complex geometries at different length scales. Finally, some representative scientific investigations are mentioned together with applications of self-organized nanomaterials in different engineering and life areas.
\end{abstract}

Keywords: nanotechnology, self-organized nanomaterials, electrochemically synthesized nanostructures

One of the fascinating aspects of science at the nanoscale is the size and shape-dependent variation in properties of matter. Comprehensive knowledge over the shape and organization of nanomaterials is a critical factor in designing devices with desired functions. Due to this, systematic efforts have been made to synthesize structures of diverse shape in the nanoscale regime and to find the various parameters that directly affect the intrinsic properties of materials at this length scale [1-4]. Selfassembling processes are common throughout nature and technology. They involve components from the molecular (crystals) to the planetary (weather systems) scale and many kinds of interactions. The concept of self-assembly is used increasingly in many disciplines, with a different flavor and emphasis in each [5]. In nanoscience, selfassembled nanostructures can be defined as spontaneously formatted nanostructures with a welldefined size distribution, while self-organization in nanoscale systems involves nanostructures natural tendency to form structures with long-range order, i.e., order at the scale much larger than the size of an individual nanostructure. Both classes are structures standing a process of internal organization at atomic level $[6,7]$. A self-assembled unity versus self-organized chain-coupled unities are schemed in figure 1.

The self-organized nanomaterials can be polymers, metals or composites and they can be organized in nanoblocks, islands, layers etc. Self-organizing nanostructures are ubiquitous in both natural and synthetic materials. They are not only appealing scientifically, by revealing the intrinsic atomic and molecular interactions that might be difficult to detect otherwise but may also hold the key for the development of novel functional structures and devices. Following the extent and complexity of organization present in all aspects of nature, biology can inspire the physical world of electronics, computing, materials science

*email: andreifeier@gmx.com; Phone: +40747501392 and manufacturing about how to organize complex functional systems that operate at molecular level. Membranes for production of inorganic nano- and microstructures [8] and programmable DNA selfassemblies for nanoscale organization of ligands and proteins [9] are just two examples of nature skills. Biological structures at macromolecular and supramolecular scales are naturally assembled and use principles of self organization; most of these structures combine lightness with tremendous strength in miniature complex mechanisms. A valuable example is that of human bone tissue. According to the recent developments in biomineralization, tens to hundreds nanodimensional crystals of a biological apatite (one of the most important components of bone tissue) are self-assembled and organized in complex structures. This process occurs under a strict control by bioorganic matrices [10].

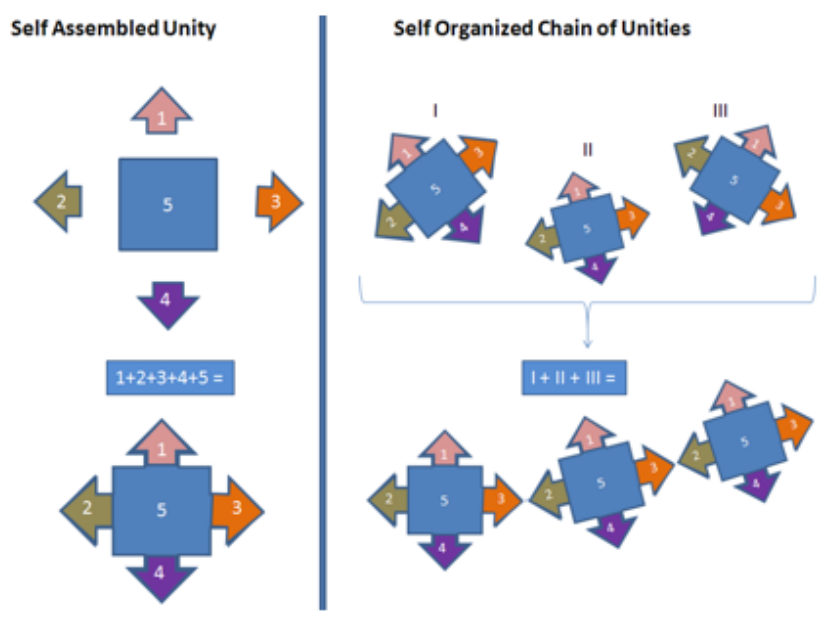

Fig. 1 Schematic representation of self-assembled unity (left) and representation of self organization for three units (right) 
The idea to design artificial materials atom-by-atom and depositindividual atoms into arrangements came after the first scientific exploration into the natural world of nanometer scale. However, it is synthetically too expensive to arrange such small units into their desired positions by hand. Materials scientists are focused on advanced techniques that afford the self-assembly and selforganization of nanoscale species into systems. Several researches have been undertaken and different methods were used for the fabrication of organized nanostructures: lithography techniques [11, 12], ion sputtering $[13,14]$, bottom-up approach [15], i.e. building up nanostructures, electrochemical methods [16, 17], template synthesis [18, 19] etc. Although some of these methods are successfully used and have given impressive results in the reproduction of self organized nano-architectures, most of the nanophenomena that rule on their formation are totally or partially unknown. Key answers for the interpretation of these peculiar events consist in interdisciplinary knowledge. Atoms behave differently and unpredictably in nano level. Let's have the example of nanoclusters. It has been observed that the growth of nanoclusters proceeds through the formation of magic number (or closed shell) clusters that exhibit unusual electronic stability. For transition metals with face center cubic structure or hexagonal close packed structure, stable clusters contain $13,55,147,309,561,923,1,415 . .$. metal atoms, where the number of surface atoms in the $n^{\text {th }}$ shell is given by $10 n^{2}+2(n=1,2,3,4,5 \ldots)[20]$. The explanation is that the high yield of magic number nanoclusters is a consequence of kinetically controlled surface grow th. That is, once these favored intermediate structures are formed, they are less reactive toward autocatalytic surface growth relative to non-magic number clusters [21].

The two fields brought together by the science of electrochemistry have been explored with great interest since historical times; from ancient electric batteries until nowadays nanomaterials, the electrochemical methods proved their practical utility and opened avenues of scientific interest. The electrochemical methods used in the fabrication of nanostructures are typically low-cost, highly effective, and they can be applied at large scale. Many materials used in consumer's product, such as metals, ceramics, polymers or composites can be manipulated to an infinite small scale through electrochemical methods, resulting in nanopores, nanoparticles, nanotubes, or nanowires. The electrochemical anodization is the most common method used in nanostructured materials synthesis and it is considered attractive, simple and effective. Electrochemical anodization involves electrolyses, anodizing, corrosion and platting processes and it has no limitation as far as sample shape and size. Through the electrochemical synthesis, materials properties can be easy controlled and eventually their self organization can be induced through a multitude of applied synthesis parameters. Scientific literature is extremely vast with respect to this subject, while electrochemical methods for the synthesis of nanomaterials is considered a technology with broad flexibility in patterning $[22,23]$.

The experimental conditions applied in the various synthesis techniques to determine the self-organization of atoms have been the subject of several investigations which opened new avenues in advanced nanostructures manufacturing. A classification of nanomaterials fabricated through electrochemical methods has not yet been done. The present work aims to make an introduction to the formation fundamentals, the fabrication and the classification of self-organized nanostructures synthesized through electrochemical methods.

\section{Experimental part}

Artificial self-organized nanomaterials: polymers, metals and ceramics

The search for new self-organized nano structured materials is a key area of contemporary research in numerous disciplines of science [24, 25]. Great attention has been paid to these types of materials with different chemical composition, produced as groups or conglomerations of nanoparticles, nanowires or nanotubes, defining nano systems. Generally, one of the following forces and mechanisms are considered responsible for the self-organization of nanostructures [26]:

-Assembly or self-organization involving biological interaction and biorecognition: in biology almost, all functional entities are self-organized structures. The operating forces in biology are very specific.

-For non-amorphous materials, crystal structure has a crucial role in determining the organization of nanoparticles. Anisotropic nanoparticles can be selectively functionalized to bring forth specific interactions between the constituent nanostructures giving diverse types of organized structures $[27,28]$.

-Tendency to aggregate due to the electrostatic repulsion between the chemical head groups or whatever type of self-organization due to electrostatic forces [29].

-Assembly or self-organization due to chemical bonding [30].

-Assembly or self-organization involving van der Waals and dipole interaction [31].

-Assembling by polymer tethering: self-organizing polymers into a predefined pattern by attaching multiple polymer arms termed as 'pom-poms' [32].

-Layer-by-layer assembly [33]. [34].

-Self-organization by surface anchored crown ethers

-Assembly induced by magnetic field [35].

-Convection as a Source of Self-Organization in Electrochemical Systems [36].

-Assembly and self-organization on templates/ substrates [37].

Nano systems exhibit interesting characteristics: quantized excitation, Coulomb blockade, single-electron tunneling (SET), and metal-insulator transition. This behavior is thought to be usual in the nanow orld, because experiments suggest that objects in the nanometer range can change shape in reasonable times, even if they are solid. This fact is crucial for the production and control of nanostructures, since these are generally obtained in outof-equilibrium conditions and are therefore meta-stable [38]. Advances in nanoelectrochemistry made possible the fabrication of a variety of artificial nanoscopic entities, such as metal and semiconductor quantum particles [39], organized mono- and multilayers of organic molecules, and various hybrid assemblies containing both organic and inorganic components [40, 41]. Currently, how ever, these so-called metamaterials are mostly limited by narrow band behavior, high losses, and limitation in making genuinely 3D materials. To overcome these problems an overlap between metamaterial concepts and materials science is necessary. In this context, engineered self-organization is presented as a future approach to metamaterial manufacturing [42]. Electrochemistry is a good perspective for engineering advanced self organized nanomaterials. Generally, the processes involved in the electrochemical fabrication of the nanostructures allow for their self-organization without additional protocols 
being needed. Let's have as an example the quantum dots. The electrochemical synthesis of quasi-periodic quantum dots and nanostructure arrays comprises few simple steps as following [43]:

- electropolishing of a substrate

- anodizing of the substrate to form an oxide layer in which nanopores will be scalloped

- deposition of a desired material into the pores

Large-scale nanoarrays can be manufactured in anodic porous alumina substrate at uniform shape, size and spacing (fig. 2 [44]). Desired magnetic metals can be electrodeposited into the nanopores. Quantum dots are lined into complex arrays placed at same distance one from the other. The self-organization process is enabled during the electrochemical synthesis, which permits the formation of pits/ nanopores placed at almost equal distance in between each other, in the alumina substrate.

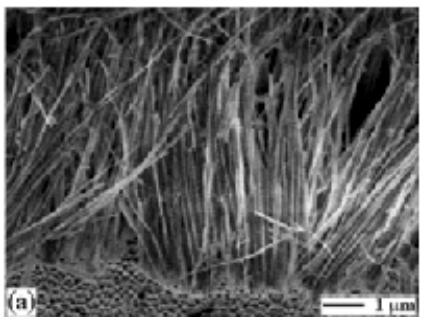

Fig. 2 SEM images of a porous alumina membrane at a magnification of (a) 1 ìm and (b) $400 \mathrm{~nm}$ (Reprinted with

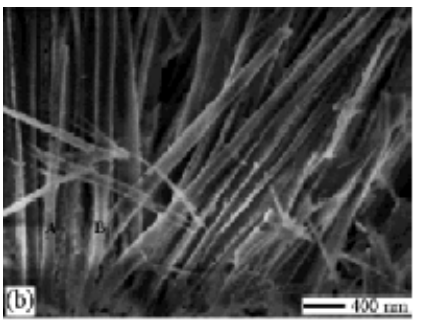
permission of Xiao Z.L. et al, Nano Lett. 2002 [44])

Furthermore, electrochemical methods are employed to produce self-organized substrates of transition metal in the nanometer region, while the particle size can be controlled in a simple manner by adjustment of some parameters (the current density, experiment duration, electrolyte type, $p \mathrm{H})$. The process makes use of an inexpensive two-electrode setup [45]. The electrochemical synthesis involves the mentioned working parameters; their correct association and interchange can lead to the fabrication of highly organized nano-substrates. Finally, polymers can also be reduced to the nano scale regime through this fabrication method. The parameters setup to get several pores densities, geometries and arrangements has been found long time ago. The anodization of Si wafers at low current densities in HF-based solutions can be used to generate an array of extremely small holes that run orthogonal to the surface, as schemed in figure 3 [46]. Bulk Si can be made microporous, mesoporous, or macroporous depending upon substrate resistivity and anodization conditions.

Due to the advantages introduced by multiple material phases, research is directed nowadays towards micro and nanocomposites [47]. Combinations of multiple phases can lead to the formation of complex self-organized nanocomposites. Ordered nanodot arrays of titanium oxides were prepared by Po-Lin Chen et al [48] (fig. 4) from TiN/Al ûlms on silicon substrate by electrochemical anodization of a TiN layer using a nanoporous anodic aluminum oxide film as template; in figures $4 a$ and $b$, the obtained titanium oxide nanodots arrays and nanoporous anodic alumina can be observed. The average size of the nanodots is about 60 $\mathrm{nm}$, which is very close to the diameter of the anodic alumina nanopores, and adjustable depending on anodization conditions. Appropriate handling of the electrochemical conditions enables the manufacturing of
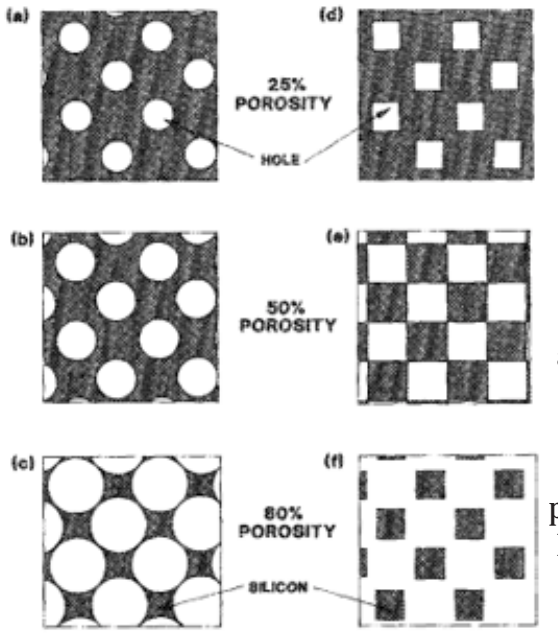

Fig. 3 Idealized plan view of an anodized

(100) Si wafer containing (a) - (c) cylindrical holed, (d)

- (f) rectangular

holes. The indicated changes in porosity are achieved by pore enlargement through chemical dissolution

(Reprinted with permission of Canham L.T., Appl. Phys. Lett. 1990[46])

self-organized nanostructures that may be further used in the organization of self-organized nanoplatforms for industrial purposes. Electrochemical methods can be applied to fabricate huge amount of self-organized foils of nanodots - nanoclusters - nanowires or nanotubes. The mechanism of self-organization allows getting same nanoarchitectural pattern on expanded surfaces, which means that electrochemical processes act following a path that is applicable to any scale.

a)

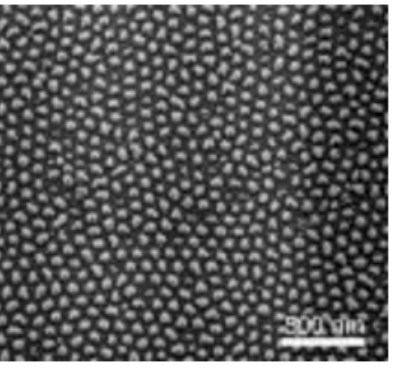

b)

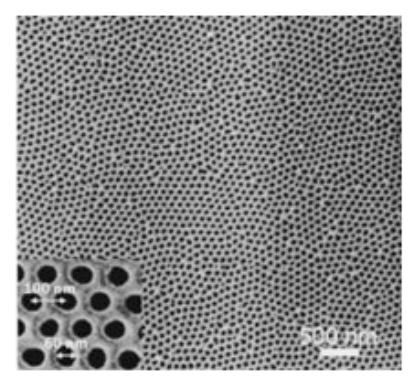

Fig. 4 Nanodots and Nanopores: a) Side-view SEM

image of titanium oxide nanodot arrays b) Top-view SEM image of the nanoporous anodic alumina ûlm after pore widening in $\mathrm{H}_{3} \mathrm{PO}_{4}$ solution. The inset shows a close-up

view of the hexagonal arrangement of the nanopores (Reprinted with the permission of Chen P.L. et al, Appl. Phys. Lett 2003 [48])

Electrochemically self-organizing processes

In self-assembly, subunits (molecules or meso-scale objects) spontaneously organize and aggregate into stable, well-defined structures based on noncovalent interactions. The information that guides the assembly is coded in the characteristics (for example, topographies, shapes, surface functionalities, and electrical potentials) of the subunits, and the final structure is reached by equilibrating to the form of the lowest free energy. Because the final self-assembled structures are close to or at thermodynamic equilibrium, they tend to reject defects. Self-assembly is the route followed in biological systems for the formation of the cell and its components. These structures are enormously complex and very small, and their formation in biological systems suggests that self-assembly may provide a route to certain types of patterned nanostructures [49]. Self-organized nanomaterials are a result off: i) the formation of nano-units and ii) the inter connection or selfarrangement of nano-units into a network. It is not known, in all cases, why exactly atoms arrange themselves to form these patterns, but they often involve interactions such as 
ionic and covalent bonding, hydrogen bonds, Brownian motion, van der Waals forces, thermal vibration, rotation, adhesive and cohesive forces and subcategories of these interactions. On the other hand, the effect of what is observed at any scale (macroscale to nanoscale) is dependent upon the priorities of these forces.

Fabricating structures at the nano level can be broken down into two main methods; top down and bottom up construction. In simple words, top-down [50] refers to building something by starting with a larger component and carving away material, like into a sculpture (e.g. patterning using photolithography and etching aw ay material, as in building integrated circuits) and bottom-up [51] refers to building something by assembling smaller components (e.g. self-assembly of atoms and molecules, as in chemical and biological systems). Electrochemical synthesis provides the advantage that nanostructures can be grown by both top down [52] and bottom up [53] techniques, and in some case both methods can be employed to create a self-organized layer such as it is in the case of $\mathrm{TiO}_{2}$ nanotube layers. Typically, the electrochemical anodization is used to manufacture semiconductor nano arrays; in between them the $\mathrm{TiO}_{2}$ nanotube arrays are most popular and the process of their synthesis is a top down technique. However, in a study for the fabrication of efficient semiconductor-sensitized bulk heterojunction solar cells Qing Wang et al [54] proposed a general synthetic strategy for spatially controlling the growth of semiconductors in the nanopores of electrically conducting materials and therefore they showed that semiconductor nanostructures can be made through an electrochemical bottom up technique which brings advantages to the manufacturing process. For both top down and bottom up electrochemical approaches, the nanoarchitecture of the structure is dictated by the geometries of the constituent molecules and the molecular interactions within and between the molecules in the surrounding liquid medium. Consequently, the ability to manipulate the spatial distribution of the molecules (or equivalently speaking, the local concentration of the molecules) is essential in directing growth in predefined directions [55].

Some prominent mechanisms are decisive in selforganization of building blocks with dimensions that are beyond the sub nanometer scale [56]:

-Attractive and repulsive interactions between building blocks and equilibrium separation

-Reversible association-dissociation and/or adaptable motion of building blocks in assemblies and lowest energy structure

-Building block interactions with solvent and interfaces -Building-block dynamics, mass transport and agitation Between them, the ones that influence more the electrochemical synthesis are the building-block dynamics, mass transport and agitation. Depending on the electrodes setup, the electrochemical synthesis is classified in different branches; nowadays the most commonly utilized methods for self organized nanostructures formation are the electrochemical deposition and the electrochemical anodizing. In the electrochemical synthesis of nanomaterials, factors as effect of electrode surface, roughness, electrostatic surface potentials and friction between dissimilar surfaces in aqueous solutions are considered as well. The electrochemical phenomena provide the ability to create precisely characterized systems such as periodically ordered structures (e.g. nanopores, nanotubes, nanowire arrays) with a periodicity lower than $100 \mathrm{~nm}$. The precise control of the surface geometry of nanostructured materials is a very important aspect with respect to their application. Mechanism involved in the electrochemical synthesis of self-organized nanomaterials and correlated factors are given in the section below.

The electrochemical synthesis requires to appropriately combining parameters with the purpose to enable specific electrochemical processes, having as result the awakening of one or more of the mechanisms listed above and some other sub categories. In nanoelectrochemistry self-organized nano-architectures can be synthesized by alternating parameters such as anodization time, anodization voltage, temperature, electrolyte type. Typical electrolysis reaction involves the transfer of charge between an electrode and a species in solution. Due to the interfacial nature of the electron transfer reactions this process involves a series of steps. The mass transfer is usually achieved through: (a) migration, (b) diffusion, and (d) convection. Migration is an electric field effect and depends upon the charge on the species, concentration and mobility in a field of force. Diffusion depends upon differences in concentration between species at the surface of the electrode and in the bulk solution. Finally, convection arises from any mechanical or thermal disturbance in the solution [57]. The repeated experimental procedures and a complete and correct manipulation of the results can lead to electrochemical syntheses of advanced self-organized nanostructures and to the standardization of performing synthesis methods in nanoelectrochemistry.

Electrochemical deposition is a deposition process in which metal ions in a solution are transported by an electric field to coat the surface of a substrate. The deposition process can be either cathodic or anodic reaction depending on the work piece to be coated (cathode or anode). Electrodeposition of nanostructures, e.g. nanocrystallines, nanocomposites, amorphous film or layered materials can be obtained by controlling the electrolysis parameters. The most commonly practiced techniques are:

i. Pulse current electrodeposition of self-organized nanostructured coating $[58,59]$ :

Directcurrent is the most commonly deployed technique to deposit a metal coating. Recent years have seen the use of pulsating the current to achieve self organized nanostructure coatings. The pulse regime parameters include pulse duty, pulse cycle, frequency and its amplitude, cathodic or anodic current, zero current at open-circuit, etc. Pulsed current can enable the incorporation of nanoparticles to a high content in the coating as well as producing a wider range of alloys, depositcomposition and material properties

ii.Nanoparticles in a metal coating to form self-organized nanocomposites [60]:

Nanosized particles can be incorporated into metallic coating to form nanocomposite coating with self-organized pattern. The inclusion of nanoparticles into a metal coating is dependent on many electrolysis parameters such as characteristics of the nanoparticle (particle concentration, surface charge, type, shape, size), electrolyte composition (electrolyte concentration, additives, temperature, $\mathrm{pH}$, surfactant type and concentration), current density (direct current, pulsed current, potentiostatic control) and flow hydrodynamics (laminar, turbulent regimes), electrode geometry and electrodeposition reactor, e.g. rotating disk electrode, rotating cylinder electrode, parallel plate electrodes, etc. A correct manipulation of electrolysis 
parameters will lead to the formation of highly organized substrates.

iii. Deployment of electrolyte additives and surfactant technology [61]:

Electrolyte additives and surfactant technology are keys to the development of self organized nanostructured materials and coatings. Additives and surfactants are deployed to affect the growth of metal deposits, via adsorption or desorption mechanisms. Many metallic coatings are conventionally designed on the macro-scale. By reducing the macro-scale to the nano-scale could provide enhanced surface properties, leading to a longer lasting, lighter weight and more protective coatings. Electrolyte additives and surfactants are used to affect the grain size of coating.

\section{Electrochemical anodizing}

The electrochemical anodizing is one of the most convenient methods used to manufacture nanostructured materials: nanopowders, nanoparticles, nanopores, nanotubes. The main advantages of this method are the simplicity, the possibility to enable the formation of self organized nanostructures and the low cost. The growth of self organized nanostructured by anodizing can be considered a selective etching. Nanostructures growth can be described in terms of a competition between several electrochemical and chemical reactions and energy processes, including: anodic oxide formation, chemical dissolution, etching/ corrosion etc.

The dimensions and integrity of the nanostructured layer/ array are strongly dependent on electrolysis parameters: potential, temperature, electrolyte composition and viscosity, anodization time, $\mathrm{pH}$, or distance between the electrodes. Generally, similar electrochemical principles are applicable for both micro and nano structures manufacturing. The electrochemical anodizing method permits the formation of mixed micro-nano self-organized structures on large metallic plates [62]. Nano-porous anodic aluminium oxide membranes with $6-19 \mathrm{~nm}$ pore diameters can be manufactured by a low-potential anodizing process [63]; the list might continue for a wide range of metals, metallic alloys, and other types of materials $[64,65]$.

\section{Results and discussions}

Classification of electrochemically synthesized nanomaterials

In general, self-organization methods in chemistry can be categorized into two diverse types. One type is selforganization under thermodynamically equilibrium conditions, in which the ordered structures are formed based on specific properties of intermolecular forces. Selfassembled structures, such as lipid-bilayers, close packed layers of nanospheres, and monolayers of thiol molecules on gold surfaces, are the representative examples. Many studies have been performed on this type of selforganization. At present, the key issues to be tackled for these methods are to improve their regularity and to be able to place nanostructures of desired size at desired location. In the other type of self-organization, the ordered structures are formed under thermodynamically nonequilibrium conditions. A wide variety of dynamic spatiotemporal orders, such as oscillations and spatiotemporal patterns, appear in self-organization manner [66].

Nanomaterials have been roughly classified according to their dimensions; this classification fits also to selforganized nanomaterials and their component units: (i)
OD nanomaterials (quantum dots, nanocrystals, nanoparticles and nanospheres); (ii) 1D nanomaterials (nanorods, nanowires, nanobelts, nanowhiskers and nanotubes), (iii) 2D nanomaterials (nanosheets, graphene, self-assemble monolayers, Langmuir-Blodgett films, layerby-layer assemblies and interfacial structures), and (iv) 3D nanomaterials (bulk materials with nanoscale structural control, nanohybrids, nanocomposites and mesoporous materials) [67].

In electrochemistry, self-organized nanostructured could be classified in diverse ways, with respect to the electrochemical method used to fabricate them, or to the material they are made of, and finally, to their nanoarchitecture.

\section{Classification with respect to the type of material}

The simplest classification of electrochemically synthesized self-organized nanomaterials separates the following main classes:

1) Nano-Ceramics

Nanoceramics can remarkably reduce the sintering densification of ceramic materials and save energy. They can also improve the behavior and increase the application reliability of ceramic materials. Nanoceramics are rarely produced through electrochemical synthesis. Hydrothermal or sol gel methods are more often used. Hydrothermal method is usually used for the fabrication of ceramic nanopowders and not for self organized substrates. On the other hand, different types of self organized nanopores or nanotubes can be doped with ceramic nanoparticles through anodization, thus resulting in some kind of hybrid self-organized ceramics [68].

\section{2) Nano-Polymers}

Template-based electrochemical methods for the synthesis of nanostructures on the basis of new redox polymers with nanowire diameters in the range of 20 "200 nm were developed in 2003 by l. Tchepournaya et al [69]. Later, in 2007, Si quantum dots, nanoparticles, nanowires, and ordered Si complex micro-/nanostructures were obtained directly from silicon wafer by a polyoxometalateassisted electrochemical method [ 70]. Efforts continue to be done in the areas of self organized nano polymeric synthesis.

\section{3) Nano-Metals}

Nanoporous and nanotubular structures can be manufactured on metal and alloy surfaces, based on selforganization. Electrochemical anodization of valve metals and their alloys forms nanoporous or nanotubular oxide layers when anodization is carried out in fluoride-containing electrolytes under optimized conditions. Morphology of porous/tubular oxide layer, that is, diameter and thickness, can be tuned by tailoring electrochemical conditions (anodization time, voltage, temperature, electrolyte type, $\mathrm{pH}$ etc.). Structures obtained strongly depend also on substrate composition-nanoporous oxide layers are formed on $\mathrm{Al}, \mathrm{Nb}, \mathrm{Ta}$ and $\mathrm{W}$ whereas nanotubular oxide layers are obtained on Ti, Zr and $\mathrm{Hf}$.

Electrochemical anodizing method is often applied for the synthesis of TiO nanotubes (called also Titania Nanotubes or by their short name TNTS, fig. 5) layers, a type of self organized substrate that became extremely known; much research was dedicated to this subject [57, $71,72]$, due to the multiple and various applications where these nanotubes could be applied. Highly self-organized nanostructures can be also synthesized through electrochemical methods on alumina, gold, zirconium or alloys $[73,74]$. 

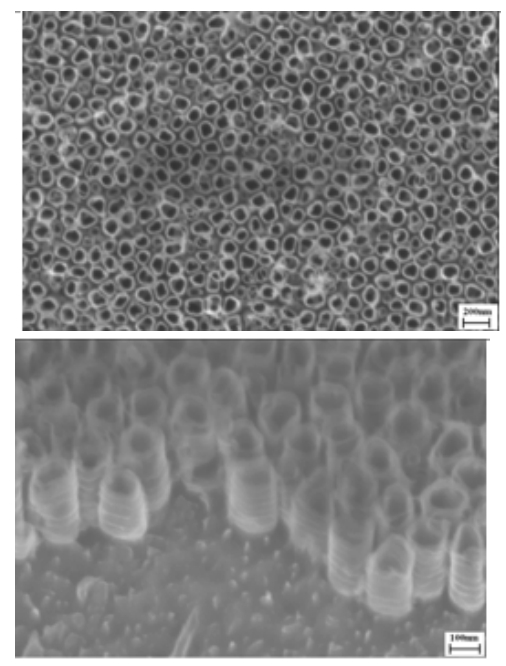

Fig. 5 Titania Nanotubes formatted after anodizing titanium in in an organic electrolyte with a low hydrofluoric content

\section{4) Nano-Composites}

Various nanotechnological methods and high number of nanostructured materials including polymer nanocomposites (PNCs) become extremely important in sensor and biosensor technology. Conducting polymer nanocomposites as artificial versatile materials seem very suitable for the development of various analyte-recognizing parts of sensors and biosensors [75]. Ordered arrays of various types of materials can be fabricated through redeposition in porous alumina mask. Through this technique, large-area of self-organized gold nanostructures formed on porous alumina templates can be grown with interparticle gaps that can be tuned both by appropriate choice of anodization technique and by the amount of deposited gold. These types of nanostructured materials can be observed in figure $6[76]$.

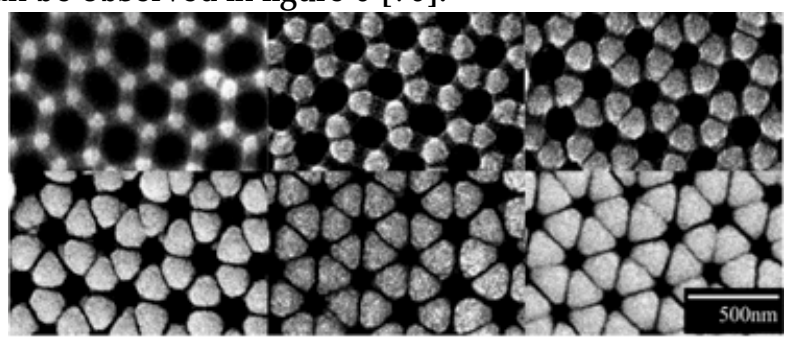

Fig. 6 SEM micrographs of the bottom of the underlying aluminum templates after gold sputter-coating the anodized substrates

(Reprinted with the permission of Nielsen P. et al, ACS Publications 2010 [76])

Further on, nano composites fabricated with the participation of two types of polymeric materials can be synthesized through differentelectrochemical approaches. Micro- and nano-structures composed of polyaniline (PANi) have been prepared by chemical and electrochemical oxidative polymerization of aniline within the pores of particle track-etched membranes (PTM) [77]. These nano substrates are not highly organized, but they are promising for future development of the technique.

\section{Classification with respect to nanoarchitecture}

With respect to their architecture, self organized nanostructures present various shapes and geometries. Different nano organizational patterns can be achieved through electrochemical methods such as self organized layers of nanodots, nanopores, nanoholes, nanotubes, nano wires, nanoparticles of different shapes and sizes, hierarchically assembled nano layers etc. All these structures present a great interest not only from the point of view of their possible applications, but also from scientific viewpoint.

\section{Applications}

Nanotechnology originated with an idea of Richard Feynman and since then had passed through many stages to reach a place where it carries a potential to spring any country's future. With its small size, nanomaterials show properties that are different from their bulk counterparts. These properties can be tailored and combined with other materials to find potential applications in the various fields of life like medicines [78], agriculture, cosmetics, energy, environmentetc. Applications of nanomaterials are already found in sensors, photonics, drug delivery, proteomics, biomolecular electronics, and homeland security, as well as in environment, in the packing industry and most important in aeronautics. Scientists are intensively working for a better comprehension of nanostructure behavior to assure a secure and correct manipulation of these types of materials.

\section{Conclusions}

The synthesis of self organized nanostructures through electrochemical methods represents a promising technology for the manufacturing of highly ordered nanomaterials. Electrochemical methods are simple and cost effective, and they enable electrochemical processes of high scientific interest. Many research groups all over the world are intensively studying the formation of self organized nanostructures under electrochemical conditions, and they work for the understanding of involved phenomena.

Advanced self organized nanostructures manufactured through electrochemical methods can vary in size and geometry and can be produced at large scales thus permitting for their application in industrial level. A correct combination of electrochemical parameters allows to produce self-organized nanomaterials; however, this combination varies depending on the requested geometry and characteristics and need a high amount of experimental observation to manage standardization.

Self organized nanostructures could be applied in any life field and they could confer new and important characteristics to any systems they are implemented. Further studies are crucial for the development of this branch of nanotechnology.

Acknowledgements: The authors would like to express their gratitude to all publishers who permitted the reuse of images for the present manuscript. This work is based on a bibliographic and experimental study supported by a grant of the Romanian National Authority for Scientific Research and Innovation, CNCS/CCCDI-UEFISCDI, project number PN-III-P2-2.1-PED-2016-0142, within PNCDI III. The current paper has been the theoretical part of the PhD thesis of the corresponding author who fulfilled requirements for the $P h D$ degree in Medical Sciences at the University of Medicine and Pharmacy TirguMures.

\section{References}

1. EL-SAYED, M.A., Acc. Chem. Res., 37, 2004, p. 326

2. PILENI, M., J. Phys. Chem., C111, 2007, p. 9019.

3. SAIVE, R., HARRY, A., Optics Express A276, 26, nr. 6, p. A275-A282. 4. TAN, Z., CHEN, S., PENG, X., ZHANG, L., GAO, C., Science, 360, nr. 6388,2018, p. 518-521.

5. HUANG, G., MEI, Y., Small, 14, 14, 2018, p. 1703665-1703665.

6. ERIC, K., Nature Reviews Molecular Cell Biology, 9, 2008, p. 255262.

7. SWIERSTRA, T., van EST, R., BOENINK, M., Nanoethics, 3, nr. 3, 2009, p. 269.

8. EDMUND B., Angew. Chem. Int. Ed. Engl., 42, 2003, p. 614-641. 9. PARK, S.H., PENG, Y., YAN, L., JOHN, H.R., THOMAS, H.L., HAO, Y., Nano Lett., 5, nr. 4, 2005, p. 729-733. 
10. SERGEY, V.D., American Journal of Biomedical Engineering, 2, nr. 3, 2012, p. 48-97.

11. WILLIAMS. G., HUNT, M., BOEHM, B., MAY, A., TAVERNE, M., HO, D., GIBLIN, S., READ, D., RARITY, J., ALLENSPACH, R., LADAK, S., Nano Research, 11, nr. 2, 2017, p. 845-854.

12. HE, Y., YAN, Y., GENG, Y., BROUSSEAU, E., Applied Surface Science, 427, Part A, 2018, p. 1076-1083.

13. KAJITA, S., KAWAGUCHI, S., OHNO, N., YOSHIDA, N., Sci. Rep., 8, nr. 1, 2018, p. 56.

14. HINKS, J.A., HIBBERD, F., HATTAR, K., ILINOV, A., BUFFORD, D.C., DJURABEKOVA, F., GREAVES, G., KURONEN, A., DONNELLY, S.E., NORDLUND, K., Sci. Rep., 8, nr. 1, 2018, p. 512.

15. KUMAR. S., BHUSHAN, P., BHATTACHARYA, S., Fabrication of Nanostructures with Bottom-up Approach and Their Utility in Diagnostics, Therapeutics, and Others, Environmental, Chemical and Medical Sensors, 1, Springer, Singapore, p. 167-198.

16. LUCAS-GRANADOS, B., SANCHEZ-TOVAR, R., FERNANDEZDOMENE, R.M., GARCIA-ANTON, J., International J ournal of Hydrogen Energy, 43, nr. 16, 2018, p. 7923-7937.

17. MARIMUTHU, T., ANANDHANA, N., THANGAMUTHU, R., Applied Surface Science, 428, 2018, p. 385-394.

18. WANG, L., JIAO, X., LIU, P., OUYANG, Y., XIA, X., LEI, W., HAO, Q., Applied Surface Science, 427A, 2018, p. 174-181.

19. XIAO, W. ZHOU, W., YU, H., PU, Y., ZHANG, Y., HU, C., Electrochimica Acta, 264, 2018, p. 1-11.

20. TEO, B.K., SLOANE, N., J. A. Inorg. Chem., 24, 1985, p. 4545.

21. W ATZKY, M.A., FINKE, R.G., J. Am. Chem. Soc., 119, nr. 43, 1997, p. 10382-10400.

22. YU, Z., YUN, F.F., WANG, X., Mater. Horiz., 5, nr. 1, 2018, p. 36-40. 23. SHARSTNIOU, A., NIAUZORAU, S., AZEREDO, B., Novel Patterning Technologies, 10584, 2018, p. 105840Y

24. SANKARAN, K.J ., FICEK, M., KUNUKU, S., PANDA, K., Yeh, C.J., Nanoscale, 10, nr. 3, 2018, p. 1345-1355

25. LI, X., ZHU, Z., NAYAKA, P.G., DUAN, J., WANG, D., Journal of Alloys and Compounds, 752, 2018, p. 68-75.

26. PANIKKANVALAPPIL, R.S., THERUVAKKATTIL, S.S., AKSHAYA, K.S., THALAPPIL, P., Nano Rev., 2, 2011, p. 5883.

27. KATO, T., MIZOSHITA, N., KISHIMOTO, K., Angew. Chem. Int. Ed. Engl., 45, nr. 1, p. 38-68.

28. ICHIKAWA, T., YOSHIO, M., HAMASAKI, A., MUKAI, T., OHNO, H., J. Am. Chem. Soc., 129, nr. 35, p. 10662-10663.

29. KOLNY, J ., KORNOWSKI, A., Weller, H., Nano Lett., 2, nr. 4, p. 361364.

30. HAINO, T., MATSUMOTO, Y., FUKAZAWA, Y., J. Am. Chem. Soc., 127, nr. 25, 2005, p. 8936-8937.

31. SAMINENI, P., GOSWAMI, D., Pramana J ournal of Physiscs, 71, nr. 6 , 2008, p. 1345-1351.

32. HORSCH, M., LAMM, M., GLOTZER, S., Nano Lett., 3, nr. 10, p. 1341-1346.

33. UGUR, S.S., SARÝÝPÝK, M., AKTAP, A.H., UCAR, M.C., ERDEN, E., Nanoscale Research Letters, 5, nr. 7, p. 1204-1210.

34. ZIMMERMAN, S.C., LAURENCE, J.L., Supramolecular Chemistry of Dendrimers, Dendrimers IV. Topics in Current Chemistry, 217, 2001, p. $95-120$.

35. MENON, L., ZHENG, M., ZENG, H., BANDYOPADHYAY, S., SELLMYER, D.J., J ournal of Electronic Materials, 29, nr. 5, 2000, p. 510-515.

36. MAKINO, T., MORIOKA, K., AOGAKI, R., J. Electroanal. Chem., 190,1985, p. $267-270$

37. STEINHART, M., Advances in Polymer Science, 220, 2008, p. 123187.

38. COMBE, N., JENSEN, P., PIMPINELLI, A., Phys. Rev. Lett., 85, nr. 1 , 2000, p. 110-113

39. YE, M., GONG, J., LAI, Y., LIN, C., LIN, Z., J. Am. Chem. Soc., 134, nr. 38, 2018, p. 15720-15723.

40. BHARATHI, S., NOGAMI, M., IKEDA, S., Langmuir, 17, nr. 1, 2001, p. 1-4.

41. KABACHII, Y.A., KOCHEV, S.Y., LENENKO, N.D., ZAIKOVSKII, V.I,, GOLUB A.S., ANTIPIN M.Y., VALETSKII P.M., Polymer Science Series, B55, nr. 1-2. p. 95-106.

42. DOROTA, A.P., TURCZYNSKI, S., GAIC, M., KOLODZIEJAK, K., DIDUSZKO, R., Advanced Functional Materials, 20, nr. 7, 2010, p. 1116-1124.
43. VALIZADEH, A., MIKAEILI, H., SAMIEI, M., FARKHANI, S.M., ZARGHAMI, N., Nanoscale Research Letters, 7, p. 480.

44. XIAO, Z.L., HAN, C.Y., WELP, U., WANG, H.H., KWOK, W.K., Nano Lett., 2, nr. 11, 2002, p. 1293-1297.

45. GIORGI, L., DIKONIMOS, T., GIORGI, R., BUONOCORE, F., FAGGIO, G., Nanotechnology, 29, 2018, p. 095604.

46. CANHAM, L.T., Appl. Phys. Lett. 57, 1990, p. 1046.

47. MOLLY, T., NATARAJAN, T.S., DIN SHEIKH, M.U., BANO, M., KHAN, F., Journal of Photochemistry and Photobiology A: Chemistry, 346, 2017, p. 113-125.

48. CHEN, P.L., KUO, C.T., Appl. Phys. Lett., 82, 2003, P. 2796.

49. YOUNAN, X., Rogers, J.A., Kateri E.P., Whitesides, G.M., Chem. Rev., 99, nr. 7, p. 1823-1848.

50. Boon, K.T., Sun, X.H., J ournal of Cluster Science, 17, nr. 4, 2006, p. 529-540.

51. EIGLER, D., From The Bottom Up: Building Things with Atoms. In: Timp G. Nanotechnology. Springer, New York, 1999, p. 425-435.

52. WAN, M.F., RAGHUNATHAN, N., ZIAIE, gB., Langmuir, 23, nr. 5, 2007, p. 2300-2303.

53. FINKE, A., POIZOT, P., GUERY, C., MAZOUZI, D., TARASCON, J.M., Advanced Functional Materials, 18 nr. 22, 2008, p. 3598-3605.

54. WANG, Q., ZHU, K., NEALE, N.R., FRANK, A.J., Nano Lett., 9, nr. 2, 2009, p. 806-813.

55. WONG, T.S., BROUGH, B., HO, C.M., Mol. Cell. Biomech., 6, nr. 1, 2009, p.1-55.

56. OZIN, G.A., ARSENAULT, A.C., CADEMARTIR, L., Nanochemistry: A Chemical Approach to Nanomaterials. Royal Society of Chemistry. Education, Cambridge, 2005, p. 820.

57. PORTAN, D.V., PAPAEFTHYMIOU, K., ARVANITA, E., JIGA, G., PAPANICOLAOU, G.C., J ournal of Materials Science, 47, 2012, p. 46964705.

58. KORNELIUS, N., MULLER, F., AN-PING, LI, GOSELE, U., Adv. Mater., 12, nr. 8, 2000, p. 586.

59. PIROTA, K.R., HERNANDEZ-VELEZ, M., NAVAS, D. J ournal of Alloys and Compounds, 369, nr. 1-2, 2004, p. 18-26.

60. SINGH, V.B., PANDEY, P., Journal of New Materials for Electrochemical Systems, 8, 2005, p. 299-303.

61. GIDDI, H.S., ARUNAGIRINATHAN, M.A., BELLARE, J.R., INDIAN J. Exp. Biol., 45, nr. 2, 2007, p. 133-159.

62. KARLINSEY, R.L., Electrochemistry Communications, 7, nr. 12, 2005, p. 1190-1194.

63. ZHANG, F., LIU, X., PAN, C., ZHU J., Nanotechnology, 18, 2007, p. 345-302.

64. MOZALEV, A., GOROKH, G., SAKAIRI, M., TAKAHASHI, H., J. Mat. Sci., 40, nr. 24, 2005, p. 6399-6407.

65. JANG, J.M., PARK, S.)., CHOI G.S., KWON, T.Y., KIM, K.H., Metals and Materials International, 14, nr. 4, 2008, p. 457-463.

66. EFTEKHARI, A., Nanostructured Materials in Electrochemistry. John Wiley \& Sons, 2008, p. 489.

67. KATSUHIKO, A., MAO, L., GARY, R.J., J ONATHAN, H.P., J Nanosci Nanotechnol, 11, nr. 1, 2011, p. 1-13.

68. NARGES, F., MAGDI, F.M, TOHRU, S., Electrochimica Acta, 54, nr. 12, 2009, p. 3255-3269

69. TCHEPOURNAYA, I., VASILIEVA, S., LOGVINOV, S., TIMONOV, A., AMADELLI R., BARTAK, D., Langmuir, 19, nr. 21, 2003, p. 9005-9012.

70. KANG, Z., J. Am. Chem. Soc., 129, nr. 17, 2007, 5326-5327.

71. PORTAN, D.V., PAPANICOLAOU, G.C., JIGA, G., CAPOSI, M., J ournal of Applied Electrochemistry, 42, nr. 12, 2012, p. 1013-1024.

72. PORTAN, D.V., KROUSTALLI, A.A., DELIGIANNI, D.D., PAPANICOLAOU, G.C. J ournal of Biomedical Materials Research Part A, 100A, nr. 10, 2012, 2546-2553.

73. PANG, Y.T., MENG, G.W., ZHANG, L.D., SHAN, W.J., ZHANG, C., GAO, X.Y., ZHAO, A.W., MAO, Y.Q., Journal of Solid State Electrochemistry, 7, nr. 6, 2003, p. 344-347.

74. SHIN, T.Y., YOO, S.H., PARK, S., Chem. Mater. 20, p. 5682-5686.

75. RAMANAVICIUS, A., Procedia Engineering, 47, 2012, 825 - 828.

76. NIELSEN, P., ALBREKTSEN, O., HASSING, S., MORGEN, P., J. Phys. Chem., C114, nr. 8, 2010, 3459-3465.

77. DELVAUX, M., Synthetic Metals, 113, nr. 3, 2000, p. 275-280.

78. ZAZGYVA, A.M., GURZU, S., JUNG, I., NAGY, O, MUHLFAY, G., POP, T.S., Rom. J. Morphol. Embryol., 56, nr. 3, 2015, p. 1085-1090. 